\title{
A polymorphism of the Corticotropin-releasing hormone receptor 2 (CRHR2) and preterm birth
}

\author{
Maximilian Schmid ${ }^{\mathrm{a}, *}$, Christoph Grimm ${ }^{\mathrm{a}}$, Heinz Leipold ${ }^{\mathrm{b}}$, Martin Knöfler ${ }^{\mathrm{a}}$, Peter Haslinger ${ }^{\mathrm{a}}$ and \\ Christian Egarter ${ }^{\mathrm{a}}$ \\ ${ }^{\mathrm{a}}$ Department of Obstetrics and Feto-maternal Medicine, Medical University of Vienna General Hospital, Austria \\ ${ }^{\mathrm{b}}$ Department of Obstetrics and Gynecology, Landeskrankenhaus Klagenfurt, Austria
}

\begin{abstract}
Our aim was to investigate whether a genetic variation in the corticotropin-releasing hormone receptor 2 gene might be associated with preterm birth. In this case-control study we evaluated the G/A polymorphism (rs2267717) in intron 2 of the corticotropin-releasing hormone receptor 2 gene in one hundred women with preterm birth and one hundred healthy women with at least one uncomplicated full term pregnancy and no history of preterm birth. No significant correlation was found between the presence of the investigated polymorphism and preterm birth $(p=0.9$, odds ratio 0.9 [Confidence interval 0.5-1.7]). A dose dependent association of the investigated polymorphism, in women with preterm birth, with gestational age at delivery ( $p=$ $0.003)$ and birth weight was observed $(p=0.0001)$. However, no association between IUGR $(n=10)$ with either one of the investigated genotypes ( $p=0.3$ ) was found. Stratified analysis within case group (i.e. PPROM vs. non-PPROM) revealed no significant difference in genotype distribution $(p=0.6)$. In conclusion, the investigated polymorphism does not increase the risk for preterm birth overall but might modulate the length of pregnancy in a dose dependent fashion in a series of Caucasian women.
\end{abstract}

Keywords: Corticotropin-releasing hormone receptor 2, polymorphism, preterm birth

\section{Introduction}

Preterm birth (PTB) remains a major cause of perinatal mortality and long term handicap in surviving infants. In industrialized countries, $5-11 \%$ of infants are born preterm $(<37$ weeks' gestation), and the rate has been increasing continuously. PTB accounts for $70 \%$ of neonatal deaths and up to $75 \%$ of neonatal morbidity, and contributes to long-term neurocognitive deficits, pulmonary dysfunction and ophthalmologic disorders [1].

Genetic factors play a strong role in PTB [2]. One of the best predictors for preterm delivery is the wom-

\footnotetext{
*Corresponding author: Maximilian Schmid, MD, Department of Obstetrics and Feto-maternal Medicine, Medical University of Vienna General Hospital, Waehringer Guertel 18-20, A-1090 Vienna, Austria. Tel.: +43 140400 2822; Fax: +43 140400 2995; E-mail: maximilian.schmid@meduniwien.ac.at.
}

en's history of a previous preterm birth [3]. In addition, a family history of preterm delivery $[4,5]$ strongly supports an underlying genetic component. In twin studies, the heritability of preterm delivery has been suggested to be as high as $40 \%$ [6].

Evidence exists that corticotropin-releasing hormone $(\mathrm{CRH})$ plays a role in the pathophysiology of preterm birth [7]. CRH, a 41-amino acid peptide, is the principal regulator of the hypothalamic-pituitaryadrenal axis. CRH activates the two G-protein-coupled corticotropin-releasing hormone receptors (CRHRs), CRHR1 and CRHR2, each with unique splicing patterns and remarkably distinct pharmacological properties, but similar signaling properties. The physiological effects of $\mathrm{CRH}$ and CRH-related agonists in target tissues depend on sufficient expression of functional CRHRs [8]. CRH is produced by fetomaternal tissues and secreted into the maternal circulation, so that dur- 
ing pregnancy the maternal plasma levels of this hormone increase while the corresponding levels of binding protein (CRHBP) decrease [9]. Patients at risk for preterm birth have elevated plasma levels of CRH and lower CRHBP levels [10]. CRHR1 and CRHR2, are expressed in human placenta, decidua, fetal membranes, endometrium, cervix and myometrium [11]. CRH is synthesized and secreted by the human placenta and might act as a "placental clock" that regulates the onset of human labor, most likely by modulating myometrial contractility $[12,13]$. Of note, the usefulness of maternal plasma CRH as a predictor of preterm birth remains controversial $[14,15]$.

To the best of our knowledge the association between corticotropin-releasing hormone receptor (CRHR) gene polymorphisms and preterm birth has not been investigated. We evaluated the role of the common maternal CRHR2 G/A gene polymorphism(rs2267717) in intron 2 to identify women who may be at higher or lower risk of preterm delivery compared with women with at least one uncomplicated pregnancy who delivered at term.

\section{Materials and methods}

\subsection{Patients}

Blood samples of 100 women with singleton pregnancies who delivered preterm consecutively were obtained from the serum bank of the Medical University of Vienna, Department of Obstetrics and feto-maternal Medicine. This included women with spontaneous PTB due to preterm labor $(26 / 100)$ or preterm premature rupture of membranes (PPROM) (55/100) as well as cases where preterm delivery was indicated for medical reasons such as intrauterine infection after PPROM (19/100). Preterm delivery was considered as delivery before 37 completed weeks of gestation. 100 women with at least one uncomplicated full term singleton pregnancy and no history of PTB, preeclampsia or stillbirth were asked to serve as controls. Gestational age was estimated from the first day of the last menstrual period and was confirmed by early ultrasound. Clinical data were obtained from files at the Medical University of Vienna. All patients were of Caucasian origin. Blood samples of cases and controls were drawn 2.4 (standard deviation 1.8) and 2.2 (1.6) days after delivery. Written informed consent was obtained from mothers before collection of biological materials. Approval was obtained by the institutional review board of the Medical University of Vienna (Reference EK Nr. 385/2004).

\subsection{Genotyping}

Genomic DNA was isolated from anticoagulated blood by using the QiAmp Blood Midi Kit, as described by the manufacturer (Quiagen, Hilden, Germany), and stored at $-20^{\circ} \mathrm{C}$. The G/A polymorphism (rs2267717) in intron 2 of the CRHR2 gene was genotyped by polymerase chain reaction - restriction fragment length polymorphism (PCRRFLP). The PCR amplification was conducted with primers flanking the gene region containing the polymorphism (5'-CAGAAAGCCTCCCAGGAATG3' and 5'-GGCTTTCTCCCTGTCTCCATC-3'). The reaction was performed in a volume of $25 \mu \mathrm{l}$, consisting of 1xPCR buffer, $200 \mu \mathrm{mol}$ of dNTP, 1,5 nmol of $\mathrm{MgCl} 2,0,5 \mathrm{U}$ TaqDNA Polymerase (Fermentas, Germany) and 40ng of genomic DNA. The concentration of each primer was $20 \mathrm{pmol} / \mu \mathrm{l}$. Cycle conditions were $94^{\circ} \mathrm{C}$ for 4 minutes; 37 cycles at $94^{\circ} \mathrm{C}$ for 30 seconds, $58^{\circ} \mathrm{C}$ for 30 seconds, $72^{\circ} \mathrm{C}$ for 3 minutes, and $72^{\circ} \mathrm{C}$ for 5 minutes. For allele detection, the PCR product was digested with the restriction endonuclease NlaIII (New England BioLabs, Beverly,MA). Fragments were separated by electrophoresis on an ethidium bromidestained agarose gel (2\%) and analyzed under UV light. The individual genotype had characteristic bands at the following molecular weights other than four common bands (257, 163, 96, and $47 \mathrm{bp}): \mathrm{G} / \mathrm{G}, 392$ and $225 \mathrm{bp}$; G/A, 617, 392, and 225 bp; A/A, 617 bp.

\subsection{Statistical analysis}

After testing for normality using KolmogorovSmirnov test, values are given as medians (interquartile range [IQR]) or means (standard deviation [SD]) where appropriate. Groups were compared using Student's ttests and chi-square tests where appropriate. Statistics have been performed accordingly. P-values and Odds Ratios (OR) with 95\% Confidence Intervals (95\% CI) were calculated wild-type/wild-type (wt/wt) vs. wildtype/mutant (wt/mt) and mutant/mutant $(\mathrm{mt} / \mathrm{mt})$, i.e., wild-type versus presence of at least one mutant allele. P-values $<0.05$ were considered statistically significant. Study's power was calculated under the assumption of a $5 \%$ type I error, 100 cases, $1 / 1$ ratio cases/controls, $25 \%$ probability of exposure in controls, and a 2.0 OR. This calculation revealed a power of $56.2 \%$ to detect an OR of 2.0. The given sample size allows for detection of an OR greater than 3 with a power of $80.2 \%$. Statistical software SPSS 11.0 for Windows (SPSS 11.0, SPSS Inc., Chicago, IL) was 
Table 1

Patients' characteristics

\begin{tabular}{lcccc}
\hline Characteristics & $\begin{array}{c}\text { Women with } \\
\text { preterm birth }\end{array}$ & $\begin{array}{c}\text { Women with full } \\
\text { term pregnancy }\end{array}$ & P-value & OR (95\%CI $)^{1}$ \\
\hline Total number of patients & 100 & 100 & - & - \\
$\quad$ Maternal age (years) & $29.1(6.6)^{2}$ & $28.8(6.4)^{2}$ & $0.8^{3}$ & - \\
History of previous preterm birth & 15 & 0 & $<0.001^{4}$ & $2.2(1.9-2.5)$ \\
Gestational age at delivery (wks.) & $29.6(2.9)^{2}$ & $39.9(1.3)^{2}$ & $<0.001^{3}$ & - \\
$\quad$ Birth weight (grams) & $1286.6(553.7)^{2}$ & $3421.9(465.4)^{2}$ & $<0.001^{3}$ & - \\
First pregnancy & 48 & 39 & $0.3^{4}$ & $1.4(0.8-2.5)$ \\
Delivery mode & & & & \\
Caesarean section & 90 & 27 & $<0.001^{4}$ & $24.3(11.1-53.5)$ \\
Spontaneous delivery & 10 & 73 & & \\
Antenatal bacterial vaginosis & 7 & 1 & $0.07^{4}$ & $7.5(0.9-61.7)$ \\
LLETZ & 3 & 1 & $0.6^{4}$ & $3.1(0.3-30.0)$ \\
Smoking & 9 & 1 & $0.02^{4}$ & $9.8(1.2-78.8)$ \\
\hline
\end{tabular}

${ }^{1}$ Odds Ratio (95\% Confidence Interval).

${ }^{2}$ Mean (Standard deviation).

${ }^{3}$ Student's t-test.

${ }^{4}$ Chi-square test.

${ }^{5}$ LLETZ: large loop excision of the transformation zone.

Table 2

Genotype and allele frequencies of the CRHR2 gene polymorphism in women with preterm birth and women with full term pregnancy

\begin{tabular}{lcccc}
\hline & $\begin{array}{c}\text { Women with } \\
\text { preterm birth }\end{array}$ & $\begin{array}{c}\text { Women with full } \\
\text { term pregnancy }\end{array}$ & P-value & OR (95\% CI) \\
\hline CRHR2 & & & & \\
$\mathrm{wt} / \mathrm{wt}$ & $77(77 \%)$ & $75(75 \%)$ & $0.9^{1}$ & $0.9(0.5-1.7)^{1}$ \\
$\mathrm{wt} / \mathrm{mt}$ & $22(22 \%)$ & $22(22 \%)$ & 0.6 & \\
$\mathrm{mt} / \mathrm{mt}$ & $1(1 \%)$ & $3(3 \%)$ & & \\
$\mathrm{Alleles}$ & $176(88 \%)$ & $172(86 \%)$ & 0.7 & $0.8(0.5-1.5)$ \\
$\mathrm{wt}$ & $24(12 \%)$ & $28(14 \%)$ & & \\
$\mathrm{mt}$ &
\end{tabular}

${ }^{1} \mathrm{P}$-value and Odds Ratio (95\% Confidence Interval) were calculated wt/wt vs. $\mathrm{wt} / \mathrm{mt}$ and $\mathrm{mt} / \mathrm{mt}$.

wt: wild type; mt: mutant.

used for statistical analysis. Power/ sample size was calculated by PS Power and Sample Size Calculations version 2.1.30 [16].

\section{Results}

Patient characteristics are shown in Table 1. Distribution of genotypes in women with preterm birth $(p=0.9)$ and term controls $(p=0.9)$ was in HardyWeinberg equilibrium. No significant association was found between the investigated CRHR2 gene polymorphism and preterm birth $(p=0.9$, odds ratio 0.9 [Confidence interval 0.5-1.7] (Table 2). In women with preterm birth, a dose dependent association of the investigated polymorphism with gestational age at delivery $(p=0.003$, wt/wt: 29.4 [2.8] weeks [wks.], wt/mt: 30.0 [3.1] wks., and mt/mt: 37.0 wks.) and birth weight was found ( $p=0.0001$, wt/wt: 1287.3 [531.2] grams [g.], wt/mt: 1214.4 [550.5] g, and $\mathrm{mt} / \mathrm{mt}: 2820.0 \mathrm{~g}$ ) (Figs 1 and 2). No association between IUGR ( $n=$ 10) with either one of the investigated genotypes ( $p=$ 0.3 ) was found. Stratified analysis within case group (i.e. PPROM vs. non-PPROM) revealed no significant difference in genotype distribution $(p=0.6)$.

\section{Discussion}

A considerable body of evidence points to a crucial role of genetics in the pathogenesis of preterm birth [2-5]. Several associations between polymorphisms in maternal genes and preterm birth have been described: Single nucleotide polymorphisms (SNP) in tumor necrosis factor, interleukin (IL)- $1 \beta$ receptor antagonist, IL-4, matrix metalloproteinase $9, \beta 2$ adrenergic receptor, vascular endothelial growth factor, and factor V Leiden are all associated with PTB [17]. 


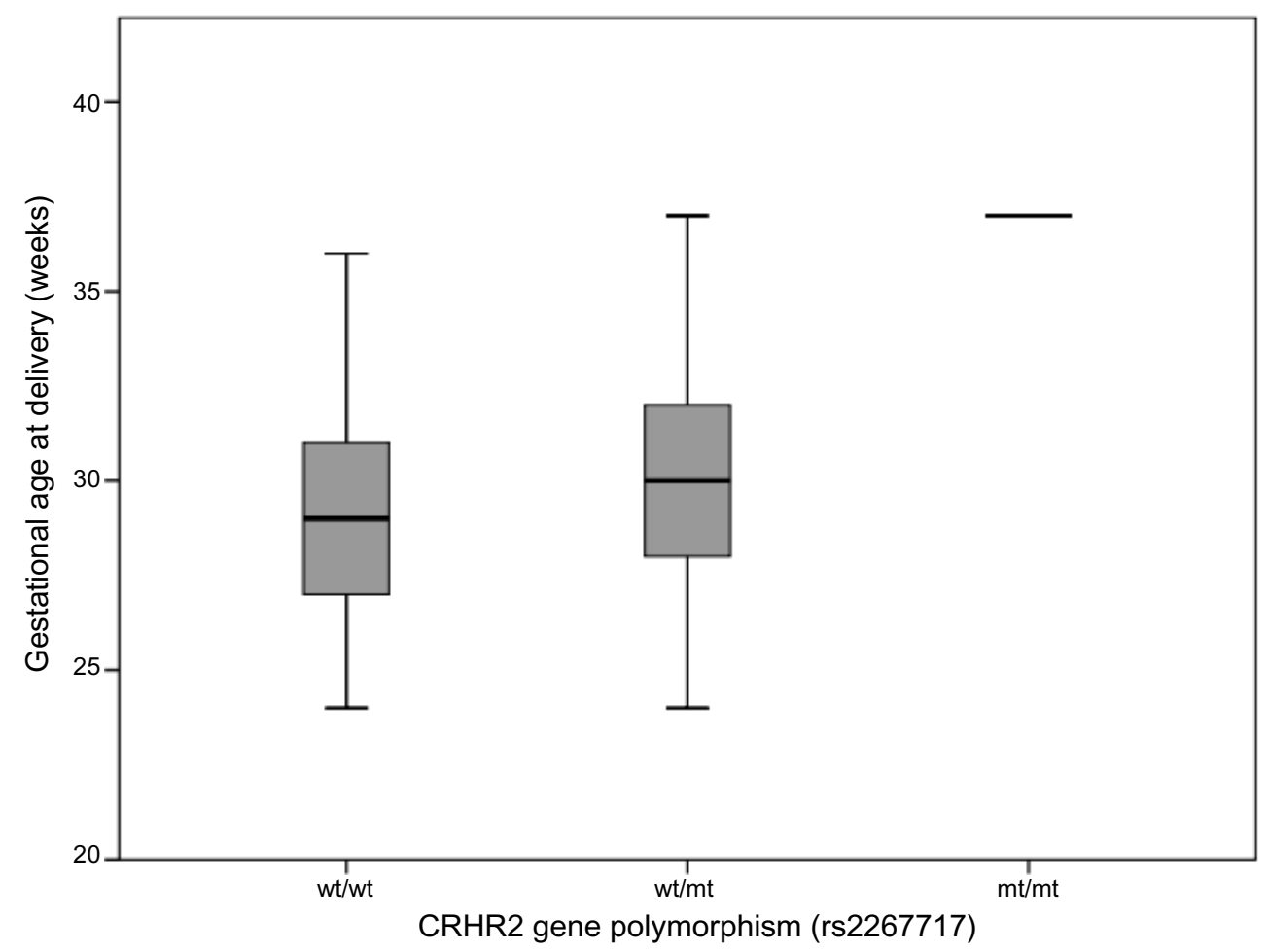

Fig. 1. CRHR2 gene polymorphism (rs2267717) and gestational age at delivery.

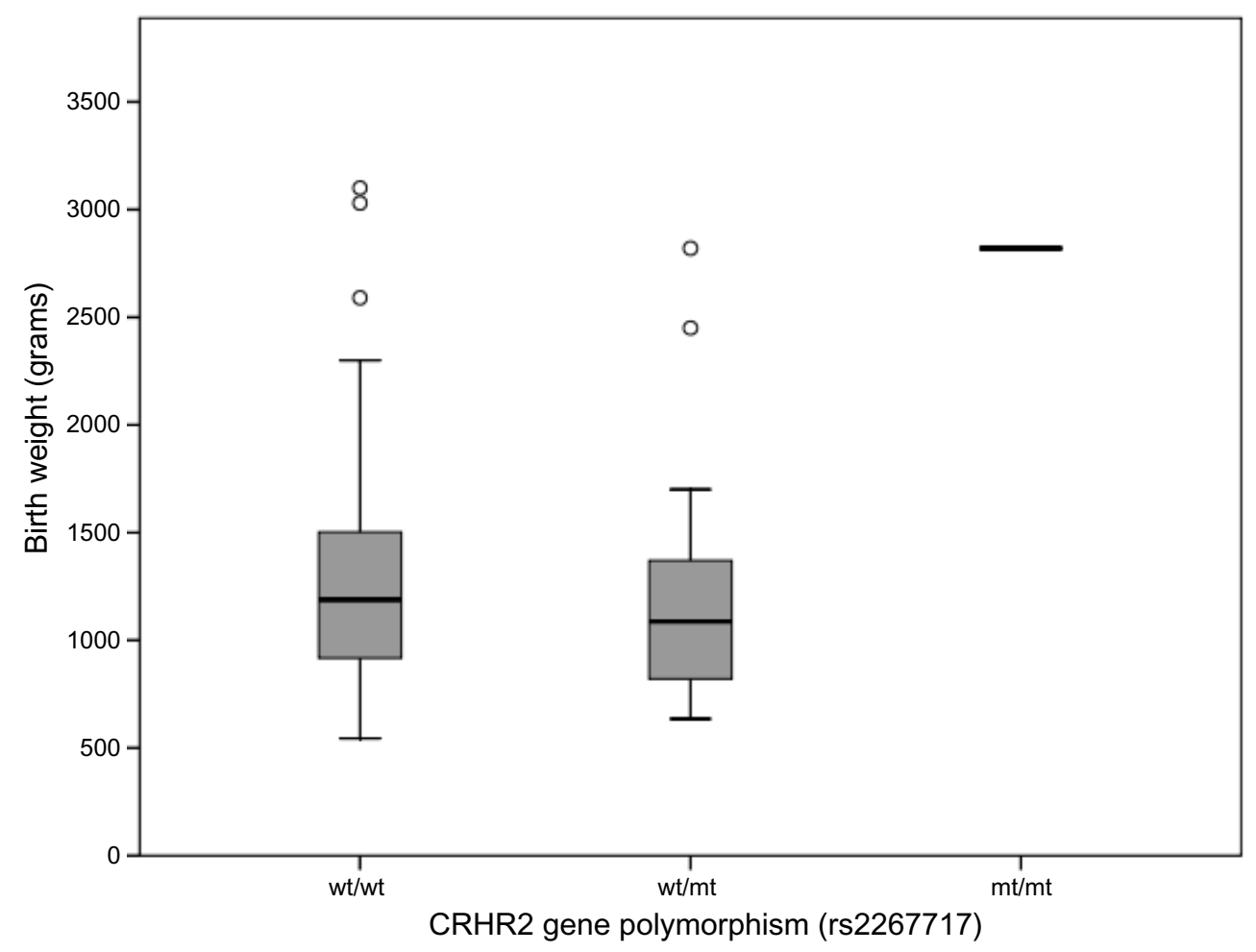

Fig. 2. CRHR2 gene polymorphism (rs2267717) and birth weight. 
Recent advances in the physiology of human pregnancy have implicated CRH and its receptors as important endocrine mediators of parturition and possibly also of fetal development $[7,13]$. To the best of our knowledge the role of CRHR gene polymorphisms in PTB have not been evaluated. We speculated that a common polymorphism within the CRHR2 gene might be associated with PTB. However, there was no significant correlation between the presence of the investigated polymorphism and PTB in our study. Interestingly we observed a dose dependent association of the investigated polymorphism with gestational age at delivery and birth weight in women with PTB. One could speculate that presence of the mutant allele influences the effect of CRH as endocrine mediator of parturition or perhaps fetal development. However, this most likely represents a random finding since further analysis revealed no association between IUGR with either one of the investigated genotypes.

However not all cases of preterm birth are related to changes in placental $\mathrm{CRH}$ production; in particular, intrauterine infection, a relatively frequent cause of preterm birth, is not associated with elevated placental $\mathrm{CRH}$ production. PTB is likely the result of various different underlying causes [18]. A single gene disorder model for PTB seems unlikely because human families with a Mendelian pattern of inheritance (i.e. autosomal dominant, autosomal recessive) for preterm delivery are difficult to identify [19]. Polymorphisms in the TNF alpha, interleukin 6, and interleukin 4 genes as well as other inflammatory mediators have [20] been successfully associated with preterm birth. However also stratified analysis within case group (e.g. PPROM vs. non-PPROM) revealed also revealed no significant difference in genotype distribution. It seems that for the majority of preterm deliveries, a genetic predisposition is more likely to occur through many genes and geneenvironment interactions. Given the current methodology and knowledge of biology, the ideal genetic study of PTB may not yet be possible. Further genome-wide and candidate gene studies have been proposed to a gain a better etiologic and biologic understanding of the hereditary components of PTB [21].

To conclude, we are the first to report on a genetic polymorphism within the CRHR 2 gene and PTB in a series of Caucasian women. Our data, however, does not support the assumption that the common G/A polymorphism within the CRHR2 gene is associated with PTB. To understand the role of CRHR polymorphisms in PTB further studies investigating additional polymorphisms of the CRHR 2 gene and other components of the CRH signaling system are needed.

\section{Acknowledgements}

We express our sincere thanks to Armin Witt, MD for his valuable assistance in conception of the study and advice in preparing the manuscript. This study was funded by the Medical Scientific Grant of the Mayor of the City of Vienna.

\section{References}

[1] S.W. Wen, G. Smith, Q. Yang and M. Walker, Epidemiology of preterm birth and neonatal outcome, Seminars in Fetal and Neonatal Medicine 9 (2004), 429-435.

[2] M.S. Esplin and M.W. Varner, Genetic factors in preterm birththe future, BJOG: An International Journal of Obstetrics and Gynaecology 112 (2005), 97-102.

[3] S.L. Bloom, N.P. Yost, D.D. McIntire and K.J. Leveno, Recurrence of Preterm Birth in Singleton and Twin Pregnancies, Obstet Gynecol 98 (2001), 379-385.

[4] T.F. Porter, A.M. Fraser, C.Y. Hunter, R.H. Ward and M.W. Varner MW, The risk of preterm birth across generations, $\mathrm{Ob}$ stet Gynecol 90 (1997), 63-67.

[5] A. Winkvist, I. Mogren and U. Hogberg, Familial patterns in birth characteristics: impact on individual and population risks, Int J Epidemiol 27 (1998), 248-254.

[6] B. Clausson, P. Lichtenstein and S. Cnattingius, Genetic influence on birthweight and gestational length determined by studies in offspring of twins, BJOG: An International Journal of Obstetrics and Gynaecology 107 (2000), 375-381.

[7] R. Smith and R.C. Nicholson, Corticotrophin releasing hormone and the timing of birth, Front Biosci 12 (2007), 912918.

[8] E.W. Hillhouse and D.K. Grammatopoulos, The molecular mechanisms underlying the regulation of the biological activity of corticotropin-releasing hormone receptors: implications for physiology and pathophysiology, Endocr Rev 27 (2006), 260-286.

[9] E.W. Hillhouse and D.K. Grammatopoulos, Role of stress peptides during human pregnancy and labour, Reproduction 124 (2002), 323-329.

[10] C.J. Hobel, C.P. Arora and L.M. Korst, Corticotrophinreleasing Hormone and CRH-binding Protein: Differences between Patients at Risk for Preterm Birth and Hypertension, Ann NY Acad Sci 897 (1999), 54-65.

[11] A. Klimaviciute, J. Calciolari, E. Bertucci, S. Belin-Tornblom, Y. Stjernholm-Vladic, B. Bystrom, F. Petraglia and G. EkmanOrdeberg, Corticotropin-releasing hormone, its binding protein and receptors in human cervical tissue at preterm and term labor in comparison to non-pregnant state, Reproductive Biology and Endocrinology 4 (2006), 29.

[12] M. McLean, A. Bisits, J. Davies, R. Woods, P. Lowry and R. Smith, A placental clock controlling the length of human pregnancy, Nat Med 1 (1995), 460-463.

[13] D.K. Grammatopoulos and E.W. Hillhouse, Role of corticotropin-releasing hormone in onset of labour, The Lancet 354 (1999), 1546-1549.

[14] C. Korebrits, M.M. Ramirez, L. Watson, E. Brinkman, A.D. Bocking and J.R.G. Challis, Maternal Corticotropin-Releasing Hormone Is Increased with Impending Preterm Birth, J Clin Endocrinol Metab 83 (1998), 1585-1591. 
[15] B. Sibai, P.J. Meis, M. Klebanoff, M.P. Dombrowski, S.J. Weiner, A.H. Moawad, A. Northen, J.D. Iams, M.W. Varner, S.N. Caritis, M.J. O’Sullivan, M. Miodovnik, K.J. Leveno, D. Conway, R.J. Wapner, M. Carpenter, B. Mercer, S.M. Ramin, J. Thorp, A.M. Peaceman and S. Gabbe, Plasma CRH measurement at 16 to 20 weeks' gestation does not predict preterm delivery in women at high-risk for preterm delivery, American Journal of Obstetrics and Gynecology 193 (2005), 1181-1186.

[16] W.D. Dupont and W.D. Plummer, PS power and sample size program available for free on the internet, Controlled Clinical Trials 18 (1997), 274.

[17] C. Hartel, D. Finas, P. Ahrens, E. Kattner, T. Schaible, D. Muller, H. Segerer, K. Albrecht, J. Moller, K. Diedrich and W. Gopel, Polymorphisms of genes involved in innate immunity: association with preterm delivery, Mol Hum Reprod 10 (2004), 911-915.
[18] E.R. Norwitz, J.N. Robinson and J.R. Challis, The control of labor, N Engl J Med 341 (1999), 660-666.

19] E. Karteris, M. Vatish, E.W. Hillhouse and D.K. Grammatopoulos, Preeclampsia is associated with impaired regulation of the placental nitric oxide-cyclic guanosine monophosphate pathway by corticotropin-releasing hormone (CRH) and CRH-related peptides, J Clin Endocrinol Metab 90 (2005), 3680-3687.

[20] M.S. Esplin, Preterm birth: a review of genetic factors and future directions for genetic study, Obstet Gynecol Surv 61 (2006), 800-806.

[21] R. Menon, S.J. Fortunato, P. Thorsen and S. Williams, Genetic associations in preterm birth: a primer of marker selection, study design, and data analysis, J Soc Gynecol Investig $\mathbf{1 3}$ (2006), 531-541. 


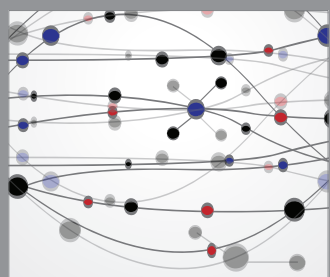

The Scientific World Journal
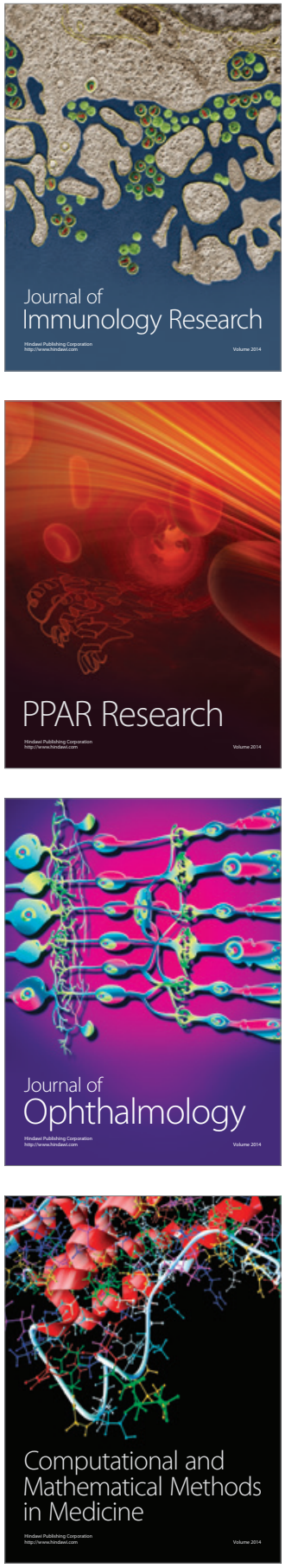

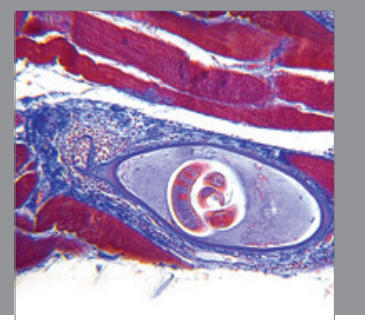

Gastroenterology

Research and Practice
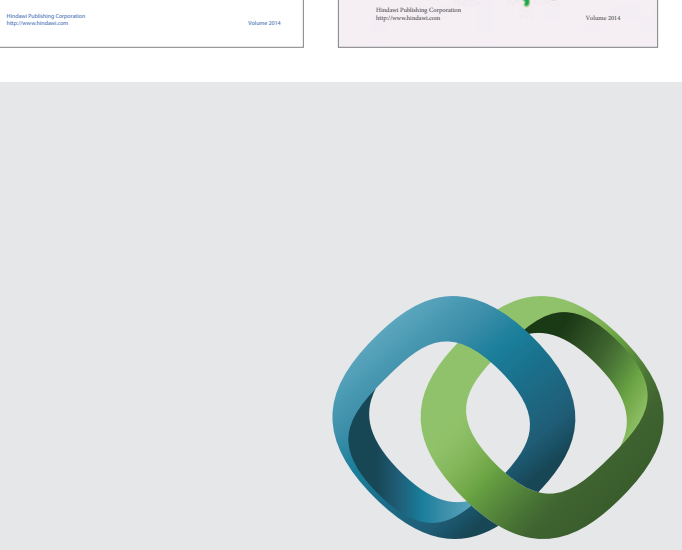

\section{Hindawi}

Submit your manuscripts at

http://www.hindawi.com
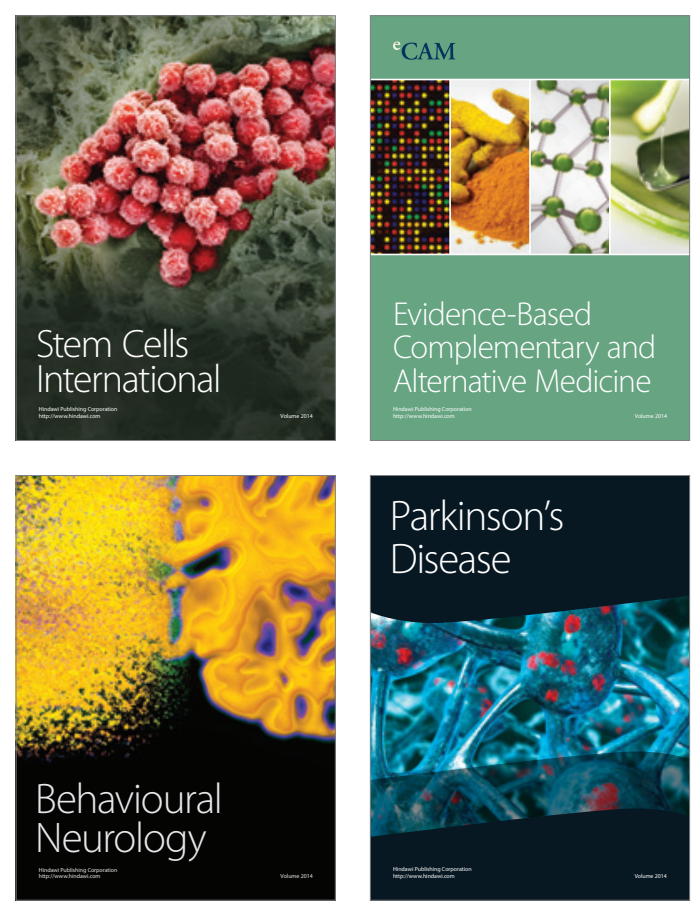

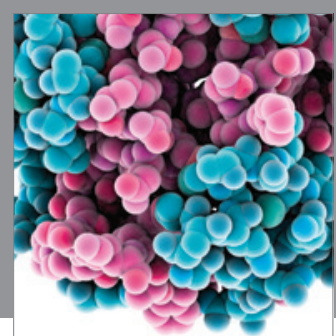

Journal of
Diabetes Research

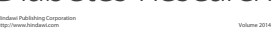

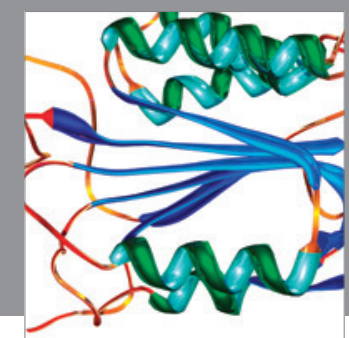

Disease Markers
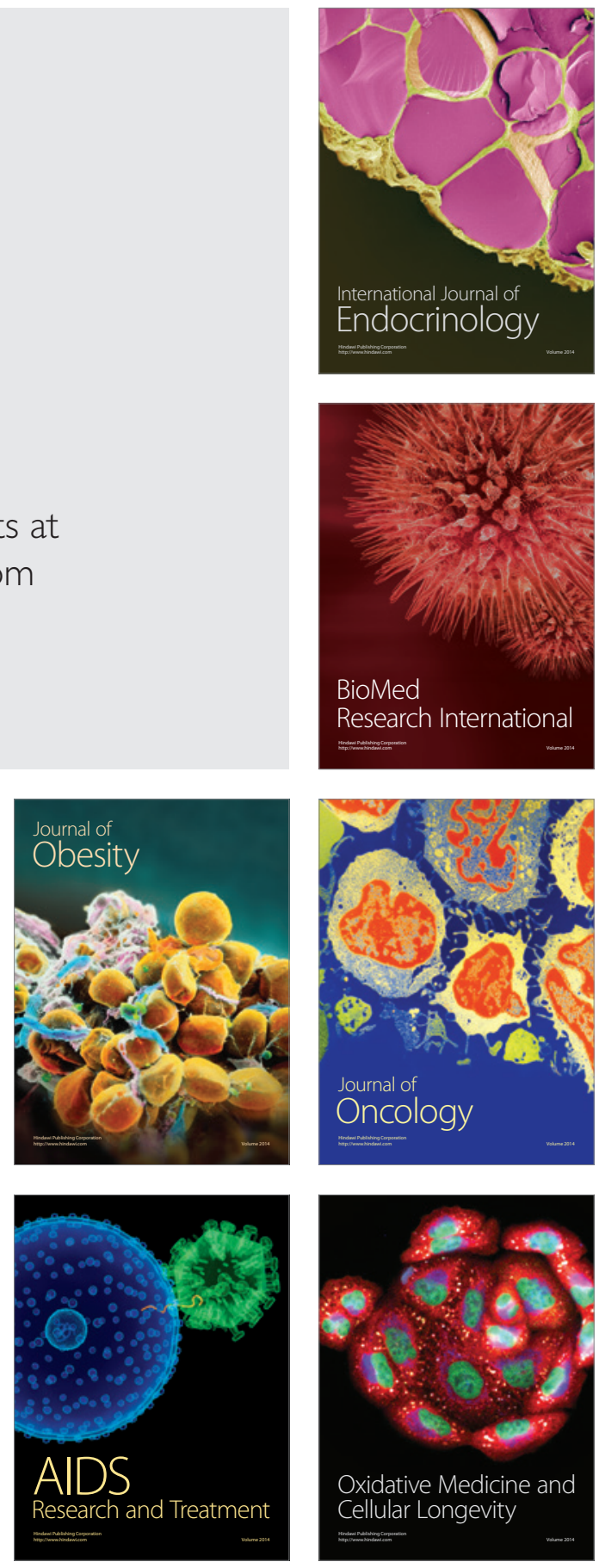